Volume 7, Issue 4, 861 - 865.

ISSN: $2165-8714$

http://www.eu-jer.com/

\title{
A Qualitative Study on the Reasons for Social Media Addiction
}

\author{
Mehmet Emin Aksoy * \\ Gaziosmanpasa University, TURKEY
}

Received: July 20, 2018 - Revised: September 10, 2018 • Accepted: September 12, 2018

\begin{abstract}
The aim of this study was to determine the causes of social media addiction of individuals, who define themselves as social media addicts, in a clearer and more concrete way. In order to achieve this aim, participants have been tested with an addiction test, and 25 university students who perceive themselves as social media addicts were selected for the study. The findings of the research showed that participants' reasons for using social media were lack of friends, social necessity of social media, feeling of fulfillment, fear of missing out, intertwining of social media and daily life. The study also pointed out that social media addiction has a beginning and a continuity phase. It has been shown that the individuals who were in the beginning phase tended to start using social media for reasons such as not being able to find friends, lack of socialization, and monotony of life. In the continuity stage of individual addiction, they stated that they use social media for reasons such as, fulfilling a duty, and protecting social relations that they had. One of the reasons for addiction was the need to socialize, while male participants were more interested in acquiring new friends, female participants were more interested in communicating with their real life friends.
\end{abstract}

Keywords: Social media, addiction, reasons for social media addiction.

To cite this article: Aksoy, M. E. (2018). A qualitative study on the reasons for social media addiction. European Journal of Educational Research, 7(4), 861-865. doi: 10.12973/eu-jer.7.4.861

\section{Introduction}

The increased use rate of technological devices resulted in behavioral addiction and strengthened technology dependency (Arpaci, Yardimci Cetin, \& Turetken, 2015; Arpaci, 2013; Arpacl, 2011). Previous studies focused on behavioral addiction and investigated the possible antecedents of the addiction. For example, a recent study suggested that locus of control and self-expressive and utilitarian benefits were antecedents of the smartphone addiction (Lee, Chang, Lin, \& Cheng, 2017). However, Chen, Zhang, Gong, Zhao, Lee, and Liang (2017) found that perceived enjoyment, mood regulation, pastime, and conformity were antecedents of the smartphone addiction. In another study, Kim and Kang (2016) reported that self-esteem and self-control were antecedents of the MMS addiction. Shen, Ng, Tan (2016) found that loneliness, achievement, and excitement were antecedents of the online game addiction. Jeong, Kim, and Lee (2017) reported that loneliness, depression, and aggression were antecedents of the digital game addiction. Yang, Liu, Wei (2016) found that online social interaction ties and online social supports were antecedents of the mobile social networking sites addiction. The previous studies suggested that there were various consequences and antecedents of the behavioral addiction.

Social media can be defined as an environment in which a group of people came together to share data, relationships and content, using internet communication channels. Social media applications appear as forums, microblogs, social networks, wikis and web applications. The most common social media tools are Facebook, Twitter, Instagram, Snapchat, WhatsApp, Google+, Wikipedia, LinkedIn and Reddit. On the other hand, behavioral addiction can be defined as "a disorder characterized by behavior that functions to produce pleasure and to relieve feelings of pain and stress, and failure to control or limit the behavior despite significant harmful consequences" (Shaffer et al., 2004). The study prefers the term "social media addiction" to connote "an impulsive-compulsive spectrum disorder" that involves social media usage (Arpaci, Kesici, \& Baloğlu, 2018; Arpaci, Baloğlu, \& Kesici, 2018; Arpaci, 2018; Arpaci, Baloğlu, Özteke Kozan, \& Kesici, 2017).

According to Baker (2016), 67\% of the people between the ages of 18 and 29 actively use social media. In addition, 22\% of all people use social media for a specific reason. According to WERSM (2016), individuals use social media to be aware of what their friends were doing, stay up to date with news and events, evaluate leisure time, find entertaining and funny content, share ideas, share videos and pictures, share information with people, meet new people.

\footnotetext{
* Correspondence:

Mehmet Emin Aksoy, Gaziosmanpasa University, Faculty of Education, Tokat / Turkey.

Email: emin.aksoy@gop.edu.tr
} 
Bridgestock (2016) compared the students' reasons for using Facebook according to the continent they lived in. The most important reason for using the Facebook was determined as catching up with the current developments. Other reasons in the importance order were to be interesting, to express what they think, and to have useful connections. Internet addiction consists of various addiction types such as game addiction, social media addiction. Social media dependence is perceived as a more specific form or subdivision of Internet addiction (Stavropoulos, Kuss, Griffiths, Wilson \& Motti-Stefanidi, 2017). The aim of the study was to determine the social media usage characteristics and reasons of the individuals who perceived themselves as problematic social media users.

\section{Method}

25 students studying at Gaziosmanpasa University School of Education were selected for the study, because previously, they took Social Media Usage Questionnaire, developed by Esgi (2016), and determined to see themselves as addicted individuals in using social media. Twelve of the students were male and thirteen were female.

The study was conducted as a qualitative research. Qualitative research requires data analysis of data gathered using information gathering methods such as interviews, document analysis, and participation observation (Creswell, 2013; Glesne, 2010). In this study, students' experience, knowledge and habits related to social media usage were analyzed. As a document analysis, e-mails sent by students and social media activities were examined. The interview form consisted of five questions. 25 students who participated voluntarily in the research answered these forms via e-mail.

Students responded to the following questions.

1. Sort your social media usage by importance?

2. What was the purpose of using social media when you started using the first social media?

3. Is there a difference in your current social media use needs compared to when you first started using it?

4. Is social media indispensable for you? If yes, why?

During the data analysis, the researcher brought together all the interview forms and students' social media related issues. These data were later organized and coded into different groups. During these processes, learning experiences, advantages and disadvantages, time have been used as categories.

\section{Findings}

The majority of the students (24 out of 25) expressed lack of friends in the first place among reasons of using social media. After a lack of friends, the vast majority of the students (22 out of 25) stated that social media was a social activity requirement. Another reason (21 out of 25) was the feeling of fulfilling a task. Another reason (20 out of 25) is that the current events was not missed. Another reason was social media (16 out of 25$)$ was intermingled with social life.

Student "A" summarizes the situation as follows.

"For me, social media is a place which I get together with my friends, to joke and spend time. I like seeing friends I see in daily life at social media too. Social media does not seem to be a very remote place for me. To be constantly aware of the developments to make correspondence, to deal with the rumors is nice. The biggest reason to use social media is that my friends are there.

Student "B" explained his thoughts in the following way.

"The main reason I use social media is to spent my free time, I have a lot of free time during the day, and I am hanging out on the social media during this time and I am happy to make new friends and chat with my real life friends, or I enjoy expressing my opinion on something and following the responses to it."

Student "C" had the following idea.

"Even with my classmates, it's interesting to share something through social media while sitting in the classroom. I think the main reason I use social media is social media is fashionable, and I think we are following the trend. I think it fulfills my need to socialize.

The student says "D".

"I have social media accounts since they started from the beginning. Honestly I have been using it for so long that I feel like social media have always existed. I can say the main reason for me is it is part of my life.

The student says "E".

"I use more text-based social media, than visual media, I like to comment and get news, so my reason to use is to follow the current events.

Another student "F" says. 
"I have been using social media for a very long time, and I have an active account since social media applications were created on the internet. The reason for my current use of social media is that I feel like I am missing something when I do not check my social media accounts.

When students listed the reasons for using the social media, at first most of the students (15 out of 25) indicated that the need to make friends. The second most expressed reason for using social media after friendship was that they do not have anything to do (10 out of 25). Student "G" refers to the subject as follows.

"I have been using social media all the time, I have been using it for a very long time. At first my initiative for using the social media was my curiosity to make new friends, nowadays I have difficulty remembering how met with most of them because they are so many.

Student says "H".

"For me, social media is starting as soon as I wake up, I open and check my page immediately. I check messages from my friends. I guess at first my reason for using social media was having fun at my leisure time.

The student says "I".

"I use social media to keep up with the news and follow the current events, I use it almost every hour of the day. I am one of social media addicts. The reason for my first social media account was my curiosity about how it would be to have social media friends"

The vast majority of students stated that the need to use social media use varied over time (20 out of 25 ). On the other hand, a small part of them (5 out of 25) stated that their purpose to use did not change over time, and it fulfills the needs they felt when they first started using it. Student "J" thinks that.

"Although at first I used social media to make friends, I do not feel this need for anymore because I have enough friends now, but if I do not use social media or check my account, I feel like there is a lack of something."

The student expresses his "K" feelings in the following way.

"The purpose of my social media use was to spend my free time at first, I still use social media to spend my leisure time. However, while I was using it four or five times a day at the beginning now I need to check my account almost every hour."

The student expresses his "L" feelings in the following way.

"I started using social media because my friends were using social media and I needed to be with them. Even though I do not interact with many of them on social media at the moment, I still use social media to be social"

A large majority of students (23 out of 25 ) stated that they would definitely not give up using social media. A small percentage of students ( 2 out of 25) stated that they would not give up but would consider giving it up if they see a valid reason to give up.

"M" from the students indicates.

"I do not think about giving social media up because I think that it contributes to my personal development, it is not harmful to me, I am having fun, I am spending time, why should I give up?"

It says " $\mathrm{N}$ " from the students.

"I do not think about giving social media up, it complements my daily life; giving it up means to cut off communication with my friends, I would give up if I only want to stop communicating with my friends, there needs to be a valid reason.

It says " 0 " from the students.

"I have social media friends that may not be my real friends but I share the same feelings and thoughts; this makes me social, and even they are more concerned than my real life friends. I definitely not consider giving it up.

It says "P" from the students.

"Give social media up!! why would I give up, it does not cost anything, I can follow the current events without watching TV, I communicate with my friends, I meet people whom I share the same thoughts, I would use it more if they make the internet connection fees a little bit more reasonable.

Social media has become a sharing platform that we use and difficult to give up in today's life. However, this situation also leads to social media addiction. Social media addiction is a subdivision of internet addiction (Kuss \& Griffiths, 
2011). The current research has identified and examined social media not from average users 'perspective but from the eyes of individuals who define themselves as social media addicts. It has been determined that a large part of the participants that too the survey was in the continuity phase and these people have used social media for at least a year.

Research findings indicate that social media addiction had a beginning and a continuity phase. It has been determined that the initial stage of dependence was the beginning of the dependency during the first six months of use, after the first six months of social media use individuals pass through the continuation phase.

\section{Results}

In this study social-media addiction reasons listed as, first lack of friends, second social media use being perceived as an activity, third fulfilling a mission, fourth following the current events and finally to be intermingled with real life. These results were consistent with the results of the studies of Bridgestock (2016) and Werste (2016). The rankings that emerged in the study did not differ between the males and the females. However, the need for socialization occurs in the form of communication with real life friends for females. In the case of males, this situation has been observed as making more new friends. This result is in agreement with the work of Lenhart (2007).

In addition, it has been determined that social media addiction has a beginning and a continuity phase. It has been found that the individuals who were in the initial stage of addiction (social media have a usage history of 6 months or less) tend to use social media for reasons such as not being able to find friends, lack of socialization, and monotony of life. Individual at the continuity phase of addiction (social media usage history is longer than 6 months) uses social media for reasons such as keeping up with the events, feeling of fulfillment of duty, protection of social relationships, etc.

\section{Recommendations}

Conscious use of individuals in the use of social media is essential. Work should be done to determine the effect of social media on health and social life. It should be ensured that the work is informed to the individuals and the knowledge levels are increased.

\section{References}

Arpacı, I. (2011). Kamu kurumlarında teknolojik inovasyon ve inovasyon politikası [Technological innovation and innovation policy in public institutions.]. METU Studies in Development, 38(2), 111-123.

Arpaci, I. (2013). Organizational adoption of mobile communication technologies (Doctoral dissertation). Department of Information System, School of Informatics, Middle East Technical University.

Arpaci, I. (2018). Culture \& nomophobia: The role of vertical versus horizontal collectivism in predicting nomophobia. Information Development. Doi: 10.1177/0266666917730119.

Arpaci, I., Baloglu, M., \& Kesici, S. (2018). A multi-group analysis of the effects of individual differences in mindfulness on nomophobia. Information Development. Doi: 10.1177/0266666917745350.

Arpaci, I., Baloğlu, M., Ozteke Kozan, H. I. \& Kesici, S. (2017). Individual differences in the relationship between attachment and nomophobia: The mediating role of mindfulness. Journal of Medical Internet Research, 19(12), e404, Doi: 10.2196/jmir.8847.

Arpaci, I., Kesici, Ş., \& Baloğlu, M. (2018). Individualism and Internet addiction: The mediating role of psychological needs. Internet Research, 28(2). Doi: 10.1108/IntR-11-2016-0353.

Arpaci, I., Yardimci Cetin, Y., \& Turetken, O. (2015). Impact of perceived security on organizational adoption of smartphones. Cyberpsychology, Behavior, and Social Networking, 18(10), 602-608.

Baker, S. (2016). Why Do People Use Online Social Networking? , http://socialnetworking.love toknow.com/Why_Do_People_Use_Online_Social_Networking the address 07.22. 2016 was accessed on.

Bridgestock, L. (2016) What Drives Students' Social Media Usage?, http://www.topuniversities.com/blog/what-drivesstudents-social-media-usage the address 05.23 .2016 was accessed on.

Chen, C., Zhang, K. Z., Gong, X., Zhao, S. J., Lee, M. K., \& Liang, L. (2017). Examining the effects of motives and gender differences on smartphone addiction. Computers in Human Behavior, 75, 891-902.

Creswell, J. W. (2013). Qualitative inquiry and research design: Choosing among five approaches, 3rd ed. Thousand Oaks, CA: Sage.

Esgi, N. (2016) Development of Social Media Addiction Test (SMAT17). Journal of Education and Training Studies, 4(10), October 2016, 174-181.

Glesne, C. (2010). Becoming qualitative researchers: An introduction, 4th ed. Boston: Pearson. 
Jeong, E. J., Kim, D. J., \& Lee, D. M. (2017). Why do some people become addicted to digital games more easily? A study of digital game addiction from a psychosocial health perspective. International Journal of Human-Computer Interaction, 33(3), 199-214.

Jones, S. R., Torres, V., \& Arminio, J. (2006). Negotiating the complexities of qualitative research in higher education: Fundamental elements and issues. New York: Routledge.

Kim, B., \& Kang, M. (2016). Effect of MMS Addiction on Users Health and Academic Performance in an Era of Convergence. Journal of Digital Convergence, 14(1), 131-139.

Kuss, D. J., \& Griffiths, M. D. (2011) Online Social Networking and Addiction-A Review of the Psychological Literature. Environ. Res. Public Health 2011, 8, 3528-3552.

Lee, Y. K., Chang, C. T., Lin, Y., \& Cheng, Z. H. (2017). Heads-down tribes across four Asian countries: antecedents of smartphone addiction. International Journal of Mobile Communications, 15(4), 414-436.

Lenhart, A. (2007) Social Networking Websites and Teens: An Overview; Washington, DC, USA: Pew Research Center.

Shaffer, H. J., LaPlante, D. A., LaBrie, R. A., Kidman, R. C., Donato, A. N., \& Stanton, M. V. (2004). Toward a syndrome model of addiction: Multiple expressions, common etiology. Harvard review of psychiatry, 12(6), 367-374.

Shen, X., Ng, J. C. Y., \& Tan, X. (2016). An empirical study on the antecedents to college student online game addiction in China. Indian Journal of Commerce and Management Studies, 7(1), pp: 8.

WERSM (2016). http://wersm.com/the-10-top-reasons-why-we-use-social-networks/ the address 07.22 .2016 was accessed on.

Werste, K. (2016). An introduction Social Networking, 4th ed. London: Moment.

Stavropoulos, V., Kuss, D. J., Griffiths, M. D., Wilson, P., \& Motti-Stefanidi, F. (2017). MMORPG gaming and hostility predict Internet addiction symptoms in adolescents: An empirical multilevel longitudinal study. Addictive behaviors, 64, pp: 294-300.

Yang, S., Liu, Y., \& Wei, J. (2016). Social capital on mobile SNS addiction: a perspective from online and offline channel integrations. Internet Research, 26(4), 982-1000. 